RESPIRATORY INFECTION

\title{
Glucose in bronchial aspirates increases the risk of respiratory MRSA in intubated patients
}

\author{
B J Philips, J Redman, A Brennan, D Wood, R Holliman, D Baines, E H Baker
}

Thorax 2005;60:761-764. doi: 10.1136/thx.2004.035766

See end of article for authors' affiliations

Correspondence to:

Dr B J Philips, Glucose and

Pulmonary Infection

Group, Jenner Wing, St

George's Hospital Medical

School, London SW17

ORE,UK; bphilips@sghms. ac.uk

Received 8 October 2004

Accepted 5 April 2005

\begin{abstract}
Background: The risk of nosocomial infection is increased in critically ill patients by stress hyperglycaemia. Glucose is not normally detectable in airway secretions but appears as blood glucose levels exceed 6.7$9.7 \mathrm{mmol} / \mathrm{l}$. We hypothesise that the presence of glucose in airway secretions in these patients predisposes to respiratory infection.

Methods: An association between glucose in bronchial aspirates and nosocomial respiratory infection was examined in 98 critically ill patients. Patients were included if they were expected to require ventilation for more than 48 hours. Bronchial aspirates were analysed for glucose and sent twice weekly for microbiological analysis and whenever an infection was suspected.

Results: Glucose was detected in bronchial aspirates of 58 of the 98 patients. These patients were more likely to have pathogenic bacteria than patients without glucose detected in bronchial aspirates (relative risk 2.4 (95\% Cl 1.5 to 3.8)). Patients with glucose were much more likely to have methicillin resistant Staphylococcus aureus (MRSA) than those without glucose in bronchial aspirates (relative risk $2.1195 \% \mathrm{Cl}$ 1.2 to 3.8)). Patients who became colonised or infected with MRSA had more infiltrates on their chest radiograph $(p<0.001)$, an increased $C$ reactive protein level $(p<0.05)$, and a longer stay in the intensive care unit $(p<0.01)$. Length of stay did not determine which patients acquired MRSA.

Conclusion: The results imply a relationship between the presence of glucose in the airway and a risk of colonisation or infection with pathogenic bacteria including MRSA.
\end{abstract}

\section{METHODS}

\section{Study design}

This is a preliminary study designed to investigate a proposed association between glucose in airways secretions and colonisation of the airways by pathogenic bacteria. It is an observational cross sectional study of newly admitted patients to a general adult ICU who require ventilatory support.

\section{Subjects}

Ninety eight critically ill patients requiring intubation and ventilation in a single centre general adult ICU were recruited to the study. Patients were derived from both medical and surgical specialities and were included if they were expected to require intubation for more than 48 hours. Patients were excluded if they were expected to die within 24 hours or if they had had a previous ICU admission during this hospital admission.

Glucose was measured simultaneously in arterial blood and bronchial aspirates. Arterial blood was analysed for glucose using a near patient glucose analyser (ABL2000, Radiometer, Copenhagen, Denmark). Bronchial aspirates were analysed for glucose at the bedside using a glucose oxidase stick, followed by more precise glucose analysis of bronchial aspirate filtrate (GM9D Analyser, Analox Instruments, London, UK). The filtrate was obtained by passing the bronchial aspirates through a $45 \mu \mathrm{m}$ bacterial filter. We have previously validated the use of the glucose oxidase sticks for use in bronchial aspirates. ${ }^{5}$ Glucose was tested for as soon after admission as possible and then on a daily basis. All measurements of glucose in bronchial aspirates were supported by blood glucose measurements. Patients were considered to be positive for glucose in their airway surface liquid after one positive result at any time.

Bronchial aspirates were sent for microbiological analysis twice weekly for MRSA surveillance (routine within our unit) and whenever a chest infection was suspected. Results were

Abbreviations: ARDS, acute respiratory distress syndrome; GLUT, glucose transporter; MRSA, methicillin resistant Staphylococcus aureus; SGLT1, sodium glucose co-transporter-1; SOFA, sequential organ failure assessment; SSA, sensitive Staphylococcus aureus 


\begin{tabular}{|lc|}
\hline Table $1 \quad$ Case mix of study patients $(\mathrm{n}=98)$ \\
\hline Speciality & Number \\
\hline Surgical & \\
Vascular surgery & 9 \\
General surgery & 27 \\
Faciomaxillary surgery & 2 \\
Trauma & 5 \\
Neurosurgery & 1 \\
Total & 44 \\
Elective procedures & 16 \\
Emergency procedures & 28 \\
& \\
Medical & \\
Respiratory medicine & 23 \\
Cardiology & 10 \\
Gastroenterology & 11 \\
Haematology & 2 \\
Neurology & 1 \\
Infectious diseases & 3 \\
Other (general medicine) & 4 \\
Total & 54 \\
\hline & \\
\hline
\end{tabular}

reported as the presence and identity of bacteria based on a simple plate count.

Severity of illness was measured using the sequential organ failure assessment (SOFA) system. Outcome was assessed at discharge from the ICU and after 6 months.

All research was carried out in accordance with the 1989 Declaration of Helsinki of the World Medical Association and was approved by the local research ethics committee.

\section{Analysis of data}

The results for the acquisition of bacteria by patients are presented as relative risk with $95 \%$ confidence intervals. Nonparametric data were analysed using Fisher's exact test (median (interquartile range)); parametric nominal data were analysed using the independent samples $t$ test (mean (range)). Outcome was measured using Cox regression with adjustment for SOFA score and age. Statistics were analysed using SPSS Version 12.0 (SPSS Inc, USA).

\section{RESULTS}

Of the 98 patients, 54 were medical and 44 surgical (table 1). All 98 patients had glucose tested in bronchial aspirates. However, 11 patients did not have samples analysed by microbiology. Two patients died unexpectedly within 24 hours, two were extubated within 48 hours, three were transferred to another hospital, and four patients did not produce sufficient sputum for analysis. These patients were excluded from all analyses of bacterial contamination.

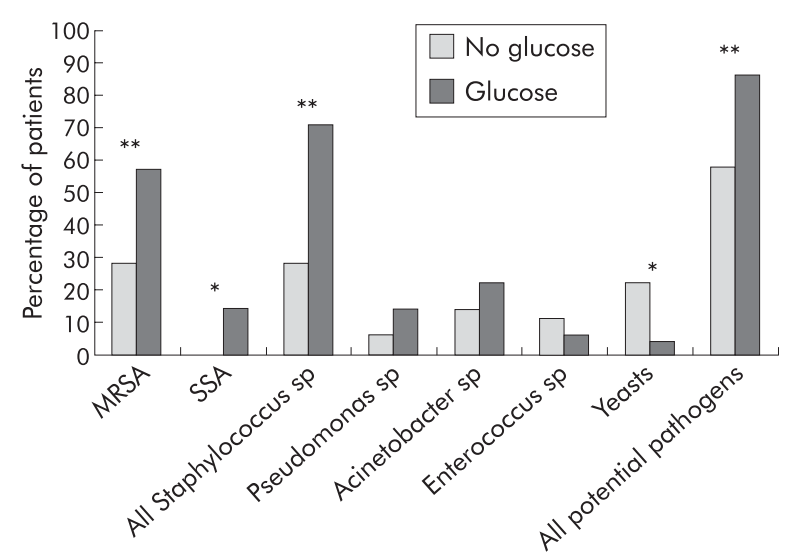

Figure 1 Bacteria identified in the bronchial aspirate samples of patients with and without glucose present in their bronchial aspirates. MRSA, methicillin resistant Staphylococcus aureus; SSA, sensitive Staphylococcus aureus; ${ }^{*} \mathrm{p}<0.05,{ }^{* *} \mathrm{p}<0.01$.

\section{Glucose}

Fifty eight patients had glucose levels of 3.5 (2.7-4.4) $\mathrm{mmol} / \mathrm{l}$ detected in bronchial aspirates (table 2). The blood glucose concentration was significantly greater in patients with glucose in bronchial aspirates than in those without (table 2). There were no significant differences between patients with and without glucose detected in terms of type of referral (surgical or medical), age, sex, or SOFA score. Of the 15 patients known to have diabetes mellitus, 11 had glucose detectable in bronchial aspirates and four did not. A total of 38 patients received treatment with steroids. Steroid use did not predict the blood glucose concentration, the appearance of glucose in bronchial aspirates, or the colonisation of bronchial aspirates with bacteria (table 2).

\section{Microbiology}

Samples of bronchial aspirates from 87 patients were analysed by microbiology; glucose was detected in bronchial aspirates of 51. Patients with glucose in the bronchial aspirates were significantly more likely to have pathogenic bacteria present: $44 / 51$ with glucose $v$ 21/36 without glucose (relative risk 2.4 (95\% CI 1.5 to 3.8$)$ ). The risk of having MRSA present was markedly increased in the presence of glucose: 29/51 with glucose $v$ 10/36 without glucose (relative risk 2.1 (95\% CI 1.2 to 3.8), fig 1). Eleven patients had MRSA detected in bronchial aspirates on admission to the ICU; 28 patients developed MRSA during their admission, 21 with glucose in the bronchial aspirates and seven without glucose detected in bronchial aspirates (relative risk 1.8 (95\% CI 1.1

Table 2 Demographic characteristics of study patients $(n=98)$

\begin{tabular}{llll}
\hline & \multicolumn{2}{l}{ Glucose in bronchial aspirates } & \\
\cline { 2 - 3 } & $\begin{array}{l}\text { Absent } \\
(\mathbf{n}=\mathbf{4 0})\end{array}$ & $\begin{array}{l}\text { Present } \\
(\mathbf{n}=\mathbf{5 8})\end{array}$ & p value \\
\hline Age (years) & $58(20-85)$ & $62(22-92)$ & 0.283 \\
Men (n) & 21 & 36 & 0.407 \\
Surgical (n) & 18 & 26 & 1.000 \\
Medical (n) & 22 & 32 & 1.000 \\
SOFA score & $8.0(2-15)$ & $8.9(4-13)$ & 0.740 \\
Hydrocortisone (n) & 16 & 22 & 1.000 \\
Diabetes mellitus (n) & 4 & 11 & 0.271 \\
Blood glucose & $6.9(4.1-10.2)$ & $8.9(3.9-12.9)$ & $0.000^{* *}$ \\
\hline SOFA, sequential organ failure assessment. & & \\
Results expressed as mean (range) or number. & & \\
**p $<0.01$. & & & \\
\hline
\end{tabular}


Table 3 Microbiological details of patients according to MRSA status

\begin{tabular}{|c|c|c|c|}
\hline & \multicolumn{2}{|c|}{ MRSA in bronchial aspirates } & \multirow[b]{2}{*}{ p value } \\
\hline & $\begin{array}{l}\text { Absent } \\
(n=48)\end{array}$ & $\begin{array}{l}\text { Present } \\
(n=39)\end{array}$ & \\
\hline Age (years) & $57(20-85)$ & $62(22-85)$ & 0.100 \\
\hline Men (n) & 28 & 27 & 0.099 \\
\hline Surgical (n) & 18 & 20 & 0.277 \\
\hline Medical (n) & 30 & 19 & 0.277 \\
\hline SOFA score & $8.2(2-15)$ & $8.2(2-14)$ & 0.969 \\
\hline Infiltrates on chest radiograph (\%) & 56 & 89 & $0.004^{\star *}$ \\
\hline Leucocytes $\left(\times 10^{9} / \mathrm{I}\right)$ & $12.9(3.1-28)$ & $15.1(6.3-40.2)$ & 0.131 \\
\hline $\mathrm{C}$ reactive protein (mg/l) & $99(14-285)$ & $137(10-290)$ & $0.031^{*}$ \\
\hline Time to MRSA (days) & $4.7(1-18)$ & $5.1(1-17)$ & 0.746 \\
\hline ICU stay (days) & $11(1-37)$ & $18(1-52)$ & $0.002^{* *}$ \\
\hline
\end{tabular}

to 3.6)). Seven patients had sensitive $S$ aureus (SSA) in their bronchial aspirates; glucose was detected in all seven and SSA was present in the initial bronchial aspirates sent to microbiology in all cases. None of the patients with SSA had or developed MRSA. The time between glucose analysis and microbiological results did not differ between patients in whom MRSA was and was not detected (table 3).

Patients were significantly more likely to have yeasts detected in bronchial aspirates in the absence of glucose (relative risk 0.4 (95\% CI 0.3 to 0.7 ) and in the absence of pathogenic bacteria (relative risk 0.3 (95\% CI 0.1 to 0.7 ). Results for other pathogens are given in fig 1.

\section{Outcome}

If MRSA was detected the length of stay in the ICU was increased by 7 days (table 3). Patients with MRSA were also more likely to have infiltrates observed on their chest radiograph and a higher $C$ reactive protein level than patients without MRSA (table 3). There was no difference in ICU outcome dependent on either the detection of glucose or MRSA. Eighty five patients were followed up for 6 months; no significant difference was seen in outcome dependent on the detection of glucose. Six month mortality was increased if MRSA was detected; however, after adjusting for age and SOFA score, the difference (although still present) was not significant.

\section{DISCUSSION}

We have shown that glucose in bronchial aspirates of critically ill patients is clearly associated with the presence of $S$ aureus and, in particular, MRSA. In most cases the detection of glucose in bronchial aspirates preceded the development of MRSA, suggesting that glucose could have caused or promoted MRSA growth. Although we were unable to quantitate the MRSA load in individual patients and thereby differentiate between colonisation and infection, the presence of MRSA was associated with infiltrates on the chest radiograph, increased levels of $C$ reactive protein, and prolonged ICU stay. These factors strongly suggest that the presence of MRSA was clinically significant. Mechanisms underlying the effect remain speculative, but both bacterial and host factors may be implicated.

In terms of bacterial factors, $S$ aureus will preferentially use glucose during the exponential phase of growth. Indeed, exit from this phase is in part determined by a lack of easily catabolisable carbohydrates. ${ }^{67}$ Glucose concentrations in standard microbiological growth media are $10 \mathrm{mmol} / \mathrm{l}$ or more. Glucose was present in the bronchial aspirates of our patients at a mean concentration of $3.5 \mathrm{mmol} / \mathrm{l}$. Whether or not this is sufficient to support growth is uncertain.
Glucose may also affect the virulence of bacteria. Escherichia coli adheres to the uroepithelial cells of diabetic patients more avidly than in non-diabetic patients. ${ }^{8}$ In $S$ aureus, glucose depresses the expression of the agr gene (involved in the regulation of virulence gene expression) during the exponential growth phase. ${ }^{9}$ In the post-exponential phase, however, regulation may be different. Glucose is known to be required for biofilm formation by $S$ aureus. ${ }^{10}$ Biofilms protect bacteria from adverse environments, thus maintaining their pathogenicity by preventing clearance from a host organism, and the importance of biofilms formed by a variety of organisms has been recognised in a number of infections. Notable examples include $S$ aureus on orthopaedic prostheses, ${ }^{11}$ Streptococcus mutans in dental caries, ${ }^{12}$ Salmonella enteritidis in gastrointestinal infections, ${ }^{13}$ and a variety of pathogens on endotracheal tubes in critically ill patients. ${ }^{14}$ The formation of biofilms has been associated with carbohydrate metabolism.

Alternatively, glucose in the airway may interfere with local immune processes. Influenza A virus has been shown to replicate more rapidly in the lungs of diabetic mice and this may be due in part to glucose causing impaired function of surfactant protein D (SpD). ${ }^{15}$ Glucose has been shown to block the carbohydrate binding domains of these proteins, essential for the recognition of incoming pathogens. Glucose decreases the respiratory burst of alveolar macrophages which could impair bacterial killing, ${ }^{16}$ but it has also been shown to enhance alveolar macrophage phagocytosis in vitro. ${ }^{16}$ Indeed, the unopsonised phagocytosis of Pseudomonas aeruginosa is increased in the presence of glucose, but only after a period of incubation of the alveolar macrophages with glucose. ${ }^{17}$

In animal diabetes models structural changes to the lung secondary to an inflammatory process have been attributed to hyperglycaemia. ${ }^{18}$ Mice with streptozocin induced diabetes mellitus developed narrowing of both pulmonary capillaries and alveoli as the extracellular matrix was enlarged by collagen bundles. The capillaries were found to contain adhered macrophages consistent with inflammation, and cells within the interstitium were enlarged and contained fat droplets. These changes were observed within 2 weeks of the onset of hyperglycaemia.

Systemic hyperglycaemia induces proinflammatory cytokine production including tumour necrosis factor $\alpha$ and interleukin 6 , possibly due to upregulation of NF- $\kappa \mathrm{B},{ }^{19}{ }^{20}$ and these in turn induce insulin resistance. ${ }^{21}$ Despite these findings, the role of glucose in lung inflammation remains uncertain. Diabetes mellitus was found to be a negative predictor for acute respiratory distress syndrome (ARDS) secondary to sepsis ${ }^{22}$ although, when hyperglycaemia was used as the predictor 
rather than a history of diabetes mellitus and the data were adjusted for confounding variables, there was no difference in the incidence of ARDS between groups.

The relationship with glucose was not observed for other bacteria, but numbers were small. Yeasts were detected significantly more often from patients without glucose and were also significantly more common in patients without pathogenic bacteria $(p=0.025)$. The absence of competing organisms and the use of antibiotics probably explain this phenomenon rather than the absence of glucose.

This study was not designed to profile glucose in the airway over time. The measurement methods were limited to intermittent sampling when the patients were productive of sputum, so patients were either found to be positive for glucose on one or more occasion or negative. Further investigation is required to fully characterise glucose in the airways of critically ill patients. We have shown previously that hyperglycaemia causes the appearance of glucose in airway secretions, ${ }^{35}$ and in this study significantly higher blood glucose concentrations were observed in patients with glucose in bronchial aspirates than in those without. However, there were patients with glucose in their bronchial aspirates who had normal or low blood glucose concentrations at the time of testing. There are a number of possible explanations for this. Glucose may be entering the airway via leaky inflamed lung tissue. In volunteers with the common cold we have shown that glucose appears in nasal secretions at normal blood glucose concentrations but is absent once the symptoms have resolved. ${ }^{5}$ Alternatively, at the point of testing, we may have missed an episode of hyperglycaemia and the glucose detected was residual from an earlier peak of concentration. Although possible, in our volunteer studies and previous animal studies glucose is readily cleared from the airway. ${ }^{3}$ Finally, glucose clearance may be impaired in critically ill patients. The most likely uptake mechanism of glucose from the airway lumen involves sodium glucose cotransporter-1 (SGLT1). ${ }^{23}$ Glucose transporters (GLUT) are also present but are of uncertain importance. The effect of sepsis on SGLTl is unknown, but lipopolysaccharide (LPS) has been shown to upregulate GLUT 1 in Kupffer cells and skeletal muscle although it has little effect on the expression of GLUT 4 in skeletal muscle cells. ${ }^{24} 25$

Nosocomial infections by resistant organisms are a serious problem for critical care medicine. Many strategies such as hand washing and patient isolation are used to decrease cross infection between patients, but little is understood about the susceptibility of an individual for acquiring organisms such as MRSA. Glucose in airway secretions secondary to acute hyperglycaemia may be such a risk factor. It remains to be seen whether the risk of acquiring MRSA can be reduced by the control of blood glucose.

\section{ACKNOWLEDGEMENTS}

The authors thank Dr Philip Sedgwick for his help and advice on the statistical analyses.

\section{Authors' affiliations}

B J Philips, A Brennan, D Wood, D Baines, E H Baker, Glucose and Pulmonary Infection Group, Jenner Wing, St George's Hospital Medical School, London SW17 ORE, UK

J Redman, Department of Anaesthesia, York Health Services NHS Trust, York YO31 8HE, UK
R Holliman, Department of Microbiology, Jenner Wing, St George's Hospital Medical School, London SW17 ORE, UK

The authors were supported by Diabetes UK for the purchase of the glucose analyser (GM9D analyser).

None of the authors has any competing interests to declare.

\section{REFERENCES}

1 Hardy KJ, Hawkey PM, Gao F, et al. Methicillin resistant Staphylococcus aureus in the critically ill. Br J Anaesth 2004;92:121-30.

2 van den Berghe $G$, Wouters $P$, Weekers $F$, et al. Intensive insulin therapy in the surgical intensive care unit. N Engl J Med 2001;345:1359-67.

3 Wood DM, Brennan AL, Philips BJ, et al. Effect of hyperglycaemia on glucose concentration of human nasal secretions. Clin Sci (Lond) 2004;106:527-33.

4 Barker PM, Boyd CA, Ramsden CA, et al. Pulmonary glucose transport in the fetal sheep. J Physiol 1989;409:15-27.

5 Philips BJ, Meguer JX, Redman J, et al. Factors determining the appearance of glucose in upper and lower respiratory tract secretions. Intensive Care Med 2003;29:2204-10.

6 Collins F, Lascelles J. The effect of growth conditions on oxidative and dehydrogenase activity in Staphylococcus aureus. J Gen Microbiol 1962;29:531-5.

7 Somerville GA, Chaussee MS, Morgan Cl, et al. Staphylococcus aureus aconitase inactivation unexpectedly inhibits post-exponential-phase growth and enhances stationary-phase survival. Infect Immun 2002;70:6373-82

8 Geerlings SE, Meiland R, van Lith EC, et al. Adherence of type 1-fimbriated Escherichia coli to uroepithelial cells: more in diabetic women than in control subjects. Diabetes Care 2002;25: 1405-9.

9 Regassa LB, Novick RP, Betley MJ. Glucose and nonmaintained pH decrease expression of the accessory gene regulator (agr) in Staphylococcus aureus. Infect Immun 1992;60:3381-8.

$10 \operatorname{Lim} \mathrm{Y}$, Jana $\mathrm{M}$, Luong $\Pi$, et al. Control of glucose- and $\mathrm{NaCl}$-induced biofilm formation by rbf in Staphylococcus aureus. J Bacteriol 2004;186:722-9.

11 Gracia E, Fernandez A, Conchello P, et al. Adherence of Staphylococcus aureus slime-producing strain variants to biomaterials used in orthopaedic surgery. Int Orthop 1997;21:46-51.

12 Li Y, Burne RA. Regulation of the $\mathrm{gtfBC}$ and $\mathrm{fff}$ genes of Streptococcus mutans in biofilms in response to $\mathrm{pH}$ and carbohydrate. Microbiology $2001 ; 147: 2841-8$.

13 Bonafonte MA, Solano C, Sesma B, et al. The relationship between glycogen synthesis, biofilm formation and virulence in salmonella enteritidis. FEMS Microbiol Lett 2000;191:31-6.

14 Baver $\Pi$, Torres A, Ferrer R, et al. Biofilm formation in endotracheal tubes. Association between pneumonia and the persistence of pathogens. Monald Arch Chest Dis 2002:57:84-7.

15 Reading PC, Allison J, Crouch EC, et al. Increased susceptibility of diabetic mice to influenza virus infection: compromise of collectin-mediated host defense of the lung by glucose? J Virol 1998;72:6884-7.

16 Kwoun MO, Ling PR, Lydon E, et al. Immunologic effects of acute hyperglycemia in nondiabetic rats. JPEN J Parenter Enteral Nutr 1997;21:91-5.

17 Wong SY, Guerdoud LM, Cantin A, et al. Glucose stimulates phagocytosis of unopsonized Pseudomonas aeruginosa by cultivated human alveolar macrophages. Infect Immun 1999:67:16-21.

18 Popov D, Simionescu M. Alterations of lung structure in experimental diabetes, and diabetes associated with hyperlipidaemia in hamsters. Eur Respir J 1997; 10:1850-8.

19 Esposito K, Nappo F, Marfella R, et al. Inflammatory cytokine concentrations are acutely increased by hyperglycemia in humans: role of oxidative stress. Circulation 2002; 106:2067-72.

20 Shanmugam N, Reddy MA, Guha M, et al. High glucose-induced expression of proinflammatory cytokine and chemokine genes in monocytic cells. Diabetes 2003;52:1256-64.

21 Cai D, Yuan M, Frantz DF, et al. Local and systemic insulin resistance resulting from hepatic activation of IKK-beta and NF-kappaB. Nat Med 2005:11:183-90.

22 Moss M, Guidot DM, Steinberg KP, et al. Diabetic patients have a decreased incidence of acute respiratory distress syndrome. Crit Care Med 2000;28:2187-92

23 Speert DP, Wong SY, Macdonald M, et al. Modulation of macrophage function for defence of the lung against Pseudomonas aeruginosa. Behring Inst Mitt 1997;98:274-82

24 Spolarics Z. Endotoxin stimulates gene expression of ROS-eliminating pathways in rat hepatic endothelial and Kupffer cells. Am J Physiol 1996;270:G660-6.

25 Vary TC, Drnevich D, Jurasinski C, et al. Mechanisms regulating skeletal muscle glucose metabolism in sepsis. Shock 1995;3:403-10. 